filtration during haemodialysis. However, similar peak plasma levels were obtained when gentamicin was given intravenously immediately before dialysis, suggesting that the size of the distribution volume of gentamicin is not affected by haemodialysis. Further, one patient (Case 2) did not require ultrafiltration during haemodialysis.

One of the major problems of intermittent haemodialysis is infection of the Scribner cannulation site. Those infections due to Gram-negative organisms are notoriously difficult to treat, and often result in loss of the cannula site (Pendras, 1964 ; Pendras and Erickson, 1966 ; Johnson et al., 1966). Previous to the present study, two shunt-site infections due to Ps. pyocyanea resulted in the loss of the shunt site within 48 hours, in spite of treatment with colistin sulphate (Colomycin). In the two patients reported here (Cases 1 and 3) there was clinical evidence of infection of the cannula site characterized by local inflammation, pain, tenderness, and the production of pus from which Ps. pyocyanea was isolated. On treatment with gentamicin there was loss of pain and tenderness, and in Case 1 the cannula continued to function normally until the 24th day, when a mycotic aneurysm ruptured, necessitating removal of the shunt. In Case 3 the cannula continued to function normally until the 26th day, when clotting of the shunt occurred. Declotting was not attempted because of the risk of septicaemia or septic pulmonary embolism; the cannula site was therefore changed.

In all previous studies with gentamicin the intramuscular route of administration had been used. When parenteral administration of any drug is required in patients undergoing intermittent haemodialysis it is advantageous to be able to give the drug intravenously rather than intramuscularly. This obviates the risk of intramuscular haemorrhage, as all such patients are heparinized during dialysis and many are on longterm anticoagulant therapy. An additional advantage of gentamicin is the small volume of fluid per dose $(1-2 \mathrm{ml}$.) that is required. All previous reports in the literature have stressed the lack of local reaction to the intramuscular administration of gentamicin. We have given gentamicin intravenously on 30 occasions in seven patients and two normal subjects. No local or systemic reactions have occurred.

\section{Summary}

Gentamicin was given intravenously to three patients with terminal renal failure treated by intermittent haemodialysis, and to two normal subjects.

Prolonged elevation of plasma gentamicin levels was observed in the patients.

The plasma disappearance rate of gentamicin was significantly increased during haemodialysis by means of a modified Kiil dialyser with cuprophane membranes (PT 150). It has been shown that gentamicin is dialysable from plasma with this membrane.

In patients undergoing twice-weekly haemodialysis on a modified Kiil dialyser with the PT 150 membrane a modified dosage schedule is required; it is suggested that $1 \mathrm{mg}$. of gentamicin per $\mathrm{kg}$. body weight be given intravenously at the end of each dialysis.

We are indebted to Dr. R. Renton and Mr. G. Poulter, of the Nicholas Research Institute Ltd., and to Mr. F. Fennell, of British Schering Ltd., for supplies of Genticin (gentamicin) and for assistance during this study, and to Sister J. M. Storey and the staff of the Renal Unit, Fulham Hospital, for their help.

\section{REFERENCES}

Barber, M., and Waterworth, P. M. (1966). Brit. med. F., 1, 203. Antimicrobial Agents and Chemotherapy, p. 138.

Brayton, R. G., and Louria, D. B. (1964). Arch. intern. Med., 114, 205 Bulger, R. J., Sidell, S., and Kirby, V. . M. M. (1963). Ann. intern. Med., 59, 593.

Curtis, J. R., and de Wardener, H. E. (1967). Israel med. F. In press.

Jao, R. L., and Jackson, G. G. (1963). Antimicrobial Agents and Chemo-

Johnson, W. J., Wagoner, R. D., Hunt, J. C., Mueller, G. J., and Hallenbeck, G. A. (1966). Mayo Clin. Proc., 41, 73.

Klein, J. O., Eickhoff, T. C., and Finland, M. (1964). Amer. F. med. Sci., 248, 528.

Pendras, J. P. (1964). Proceedings of the Working Conference on Chronic Dialysis. University of Washington, Seattle.

- and Erickson, R. V. (1966). Ann. intern. Med., 64, 293.

Rosselet, J. P., et al. (1963). Antimicrobial Agents and Chemotherapy,

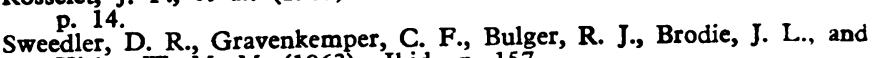
Kirby, W. M. M. (1963). Ibid., p. 157.

Weinstein, M. J., et al. (1963). f. med. pharm. Chem., 6, 463.

\title{
Intrathecal Gentamicin in Treatment of Ventriculitis in Children
}

\author{
R. L. NEWMAN,* M.D.; R. J. HOLT,† M.I.BIOL., F.I.M.L.T.
}

Frit. med.9., 1967, 2, 539-542

The risk of severe infection of the ventricles and meninges by Gram-negative bacteria appears inseparable from extensive neurosurgical procedures. Infection with many strains of Pseudomonas can be successfully treated by the use of intrathecal and intramuscular polymyxin B methane sulphonate (Newman and Stewart, 1964), but a high proportion of the enterobacteriaceae found in these sites are not sensitive to antibiotics suitable for intrathecal therapy.

Reports from many workers (Weinstein et al., 1963 ; Jao and Jackson, 1964 ; Klein et al., 1964) of the unusual antibacterial spectrum and bactericidal effect of gentamicin sulphate suggested that this new antibiotic might be of use in such conditions, and we report here the successful treatment of three patients with meningitis and ventriculitis associated with meningomyeloceles.

\footnotetext{
* Consultant Pathologist, Queen Mary's Hospital for Children, Carshalton,

+Chief Technician, Queen Mary's Hospital for Children, Carshalton,
Surrey.
}

Results of treatment in such a small series must leave many questions unanswered, but the information obtained and the successful outcome in all three cases may be of interest and. we feel, warrant presentation at an early stage. For this reason the laboratory findings are given in some detail.

Gentamicin is derived by ${ }^{*}$ submerged fermentation from a new species of the genus Micromonospora purpurea (Weinstein et al., 1963) and was isolated in the research laboratories of the Schering Corporation, New Jersey. Chemically it consists of two isomeric pseudo-oligosaccharides related to the neomycinparomomycin-kanamycin group of antibiotics (Rosselet et al., 1963 ; Weinstein et al., 1963). Extensive in-vitro tests show that, in addition to activity against many of the common pathogenic Gram-negative bacteria, gentamicin also inhibits all strains of Staphylococcus aureus tested (Barber and Waterworth, 1966). Clinical trials of the antibiotic demonstrate its value in the treatment of urinary infections caused by Gramnegative bacteria (Jao and Jackson, 1964), especially those caused by pseudomonads, and in the treatment of pseudomonas 
burn sepsis (Stone et al., 1965). Klein et al. (1964) reported the successful control of a pseudomonas meningitis in a premature infant with meningomyelocele with intramuscular gentamicin. In all publications the possibility of severe vestibular damage is mentioned, though Jao and Jackson (1964) suggest that this is always associated with pre-existing renal failure or with high dosage.

\section{Methods}

Gentamicin sulphate supplied as a reference compound is a white powder freely soluble in water ; the batch of powder used had a labelled potency of $579 \mu \mathrm{g}$. of gentamicin activity per 1 mg. of gentamicin sulphate (based on a moisture content of $9.5 \%)$. The powder is avidly hygroscopic, so great care must be taken to keep it under anhydrous conditions. A $10 \%$ stock solution $(100 \mathrm{mg} . / \mathrm{ml}$.) of the base $(172 \mathrm{mg}$. of gentamicin sulphate per ml.) was made in distilled water ; this was prepared monthly and stored in dec p-freeze, weekly assays showing no loss of potency. The dry powder can be autoclaved without loss of activity, though, since no bacterial contamination occurred, this was not necessary.

The presentation of gentamicin sulphate supplied for intramuscular use (40 mg. of gentamicin base per ml.) contains methyl and propyl hydroxybenzoates and sodium metabisulphate as preservatives, and was therefore thought to be unsuitable for intrathecal use. For this purpose $172 \mathrm{mg}$. of gentamicin sulphate powder was dissolved in $10 \mathrm{ml}$. of sterile pyrogen-free water to give a final concentration of $1 \mathrm{mg}$. of gentamicin base per $\mathrm{ml}$. and filtered through a small cellulose acetate membrane. This solution was tested for sterility; assay showed that no loss of antibacterial activity resulted from membrane filtration.

\section{Sensitivity Tests}

Discs.-Sensitivity discs containing $5 \mu \mathrm{g}$. of gentamicin base per disc were prepared, rapidly dried in vacuo, and stored at $4^{\circ} \mathrm{C}$. No loss of activity under standard conditions towards the Oxford staphylococcus (N.C.T.C. 6571) was noted during three months' storage at this temperature. Even lawns of bacterial growth were cultured on infusion agar plates, an inoculum of $0.3 \mathrm{ml}$. of suspension in infusion broth containing about $10^{6}$ organisms $/ \mathrm{ml}$. being used.

Minimum Inhibitory and Bactericidal Concentration.Gentamicin sulphate was incorporated in 2-ml. volumes of infusion broth to give a range of final concentrations of $0,1,2$, 5,10 , and $20 \mu \mathrm{g} . / \mathrm{ml}$. The inoculum was prepared from several apparently identical colonies of the organism under investigation and was added to each tube to give a final concentration of $10^{6}$ organisms per millilitre. After incubation for 18 hours the tube containing the least amount of antibiotic with no visible growth gave the minimum inhibitory concentration. Standard loop plate-outs were made from each tube on to MacConkey agar plates. The least amount of antibiotic which prevented regrowth during 24 hours' incubation was regarded as the minimum bactericidal concentration.

\section{Drug Assay}

The use of Bacillus subtilis (Jao and Jackson, 1964), staphylococcus 209P, or Sarcina lutea (Klein et al., 1964) has been suggested for the microbiological assay of gentamicin. These organisms were tested, but in our hands were inferior to Corynebacterium xerosis (N.C.T.C. 9755), which has proved highly satisfactory in assays by the fish-spine bead method. This method, first proposed by Lightbown and Sulitzeanu (1957), is particularly valuable in paediatric cases, since volumes as low as $0.02 \mathrm{ml}$. of biological fluid can be reliably assayed. All assay standards were prepared in water because there is considerable discrepancy between reports on the effects of high concentrations of serum and whole blood on gentamicin activity. Our own investigations to date suggest that gentamicin activity is in fact enhanced in the presence of $50 \%$ and $100 \%$ serum. This finding is confirmed in a report from Dr. H. Wahlig (1966), Merck A.G., Darmstadt, and parallels similar effects with kanamycin and neomycin; it appears to contradict the suggestion of protein-binding by other workers (Klein et al., 1964 ; Barber and Waterworth, 1966).

\section{Preliminary Laboratory Investigations}

Routine clinical isolates of Gram-negative bacteria from all sources were tested against gentamicin-sensitivity discs (Table I). Zones of inhibition with diameters over $15 \mathrm{~mm}$. were regarded as fully sensitive, zones between 10 and $15 \mathrm{~mm}$. showed restricted sensitivity, and organisms with zones below $10 \mathrm{~mm}$. were regarded as resistant.

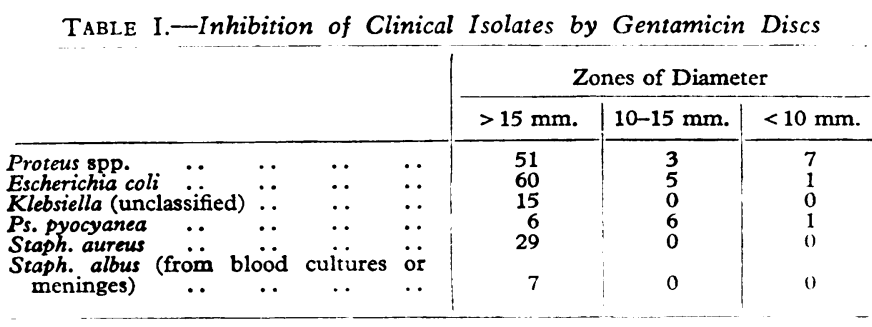

TABle II.-Sensitivity to Gentamicin

\begin{tabular}{|c|c|c|c|c|c|c|c|}
\hline \multirow{2}{*}{ Organism } & \multirow{2}{*}{ Total } & \multicolumn{6}{|c|}{ Gentamicin Concentration $(\mu \mathrm{g} . / \mathrm{ml})}$. \\
\hline & & $<1$ & $1-2$ & $2-5$ & $5-10$ & $\mid 10-20$ & $>20$ \\
\hline Proteus spp. & $13\left\{\begin{array}{l}\text { M.I.C. } \\
\text { M.B.C. }\end{array}\right.$ & $\begin{array}{l}5 \\
1\end{array}$ & $\begin{array}{l}4 \\
1\end{array}$ & $\begin{array}{l}2 \\
5\end{array}$ & $\frac{1}{3}$ & $\frac{1}{3}$ & $=$ \\
\hline E. coli & $7\left\{\begin{array}{l}\text { M.I.C. } \\
\text { M.B.C. }\end{array}\right.$ & $\begin{array}{l}5 \\
1\end{array}$ & $\frac{1}{3}$ & $\sqrt{2}$ & 二 & $\underline{2}$ & $\overline{1}$ \\
\hline Klebsiella .. & $8\left\{\begin{array}{l}\text { M.I.C. } \\
\text { M.B.C. }\end{array}\right.$ & $\begin{array}{l}7 \\
2\end{array}$ & $\begin{array}{l}1 \\
4\end{array}$ & $\sqrt{2}$ & 二 & 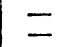 & $=$ \\
\hline Ps. pyocyanea & $13\left\{\begin{array}{l}\text { M.I.C. } \\
\text { M.B.C. }\end{array}\right.$ & 2 & 5 & $\begin{array}{l}5 \\
3\end{array}$ & $\overline{2}$ & $\frac{1}{6}$ & $\overline{2}$ \\
\hline
\end{tabular}

A proportion of the isolates shown in Table I, including all cases where gentamicin was contemplated, were further tested in liquid medium (Table II). The results indicated that many infections due to these organisms might be amenable to treatment with gentamicin provided effective levels could be attained in vivo.

\section{Clinical Observations}

Treatment of a number of patients with urinary infections due to these organisms was begun, and will be the subject of another publication.

Three patients with meningitis and ventriculitis were treated with gentamicin.

\section{Case 1}

A baby aged 3 months had had a meningocele repaired and a Spitz-Holter valve inserted, after which meningitis due to $P$ s. pyocyanea developed. This was treated successfully with polymyxin B methane sulphonate. The cerebrospinal fluid remained sterile for two weeks and a new valve was inserted. After this the ventriculitis recurred and the C.S.F. again grew Ps. pyocyanea.

The minimum inhibitory concentration of gentamicin was 1-2 $\mu \mathrm{g} . / \mathrm{ml}$. and the minimum bactericidal concentration $2-5 \mu \mathrm{g} . / \mathrm{ml}$. Intramuscular administration of gentamicin was started at the normal dose of $1 \mathrm{mg} . / \mathrm{kg}$./day in three eight-hourly doses, and $100 \mu \mathrm{g}$. was injected intraventricularly with no apparent ill-effects 
Fig. 1). Examination of the C.S.F. after 24 hours showed a low level of gentamicin (less than $1 \mu \mathrm{g} . / \mathrm{ml}$.) and no detectable serum level. The C.S.F. culture was still positive.

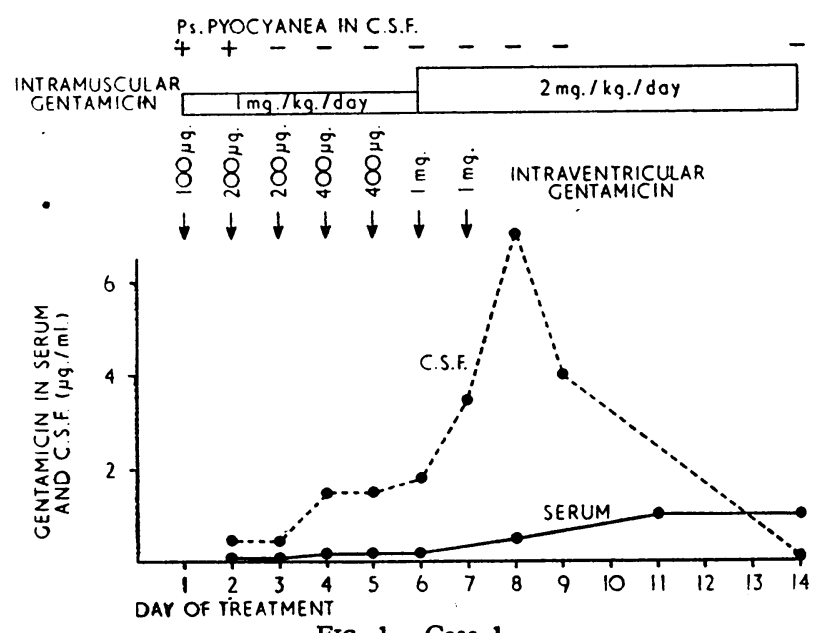

FIg. 1.-Case 1

Intramuscular dosage continued at the same rate for another four days, during which the daily intraventricular dose was increased to $200 \mu \mathrm{g}$. and then to $400 \mu \mathrm{g}$. On the third day of treatment the C.S.F. from the ventricles was sterile and the culture never again became positive. On the sixth day the intraventricular dose was increased to $1 \mathrm{mg}$. with no ill effect, and, though raps at short intervals after a dose revealed higher C.S.F. levels, these fell rapidly during the succeeding 24 hours.

The intramuscular dose was then doubled ( $2 \mathrm{mg} . / \mathrm{kg} . /$ day), and for the next three days higher C.S.F. levels were obtained (from 2 to $7 \mu \mathrm{g} . / \mathrm{ml}$.). Intraventricular administration then ceased and the C.S.F. levels fell away to nil, but on continuing intramuscular dosage at the higher level serum assays gave results of $1 \mu \mathrm{g} . / \mathrm{ml}$. Colonization of the valve had occurred during the ventriculitis, and, as expected, had persisted throughout treatment. The valve was changed again under cover of intramuscular therapy alone and no recurrence of the infection occurred.

Levels of gentamicin in the urine throughout the course of treatment varied widely, but would probably have been inadequate for the treatment of a sensitive urinary infection until the intramuscular dose was doubled.

The blood urea varied during treatment between 33 and $39 \mathrm{mg}$./ $100 \mathrm{ml}$., and no significant change in the blood picture or urine were seen. The C.S.F. protein and cells fell slowly during treatment, and no pleocytosis or rise in protein was seen as a result of the intraventricular injections.

\section{Case 2}

A baby with a meningomyelocele closed on the day of birth developed ventriculitis due to $\mathrm{Kl}$. aerogenes 10 days after operation. Gentamicin was begun immediately at the standard dose of $1 \mathrm{mg}$./ kg./day with $0.5 \mathrm{mg}$. daily intraventricularly (Fig. 2).

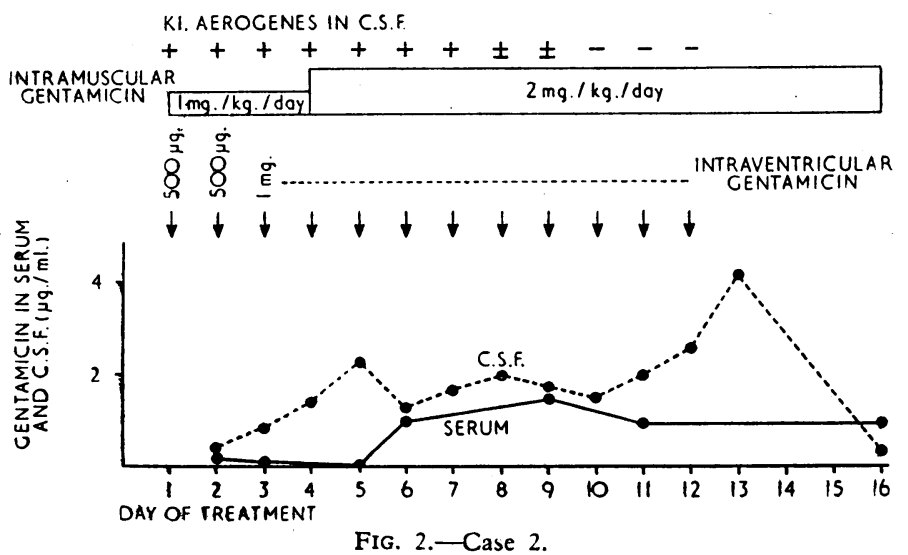

After two dnys the C.S.F. culture was still positive, and insignificant serum levels were found. Assay of gentamicin in the C.S.F. showed a residual level of less than $1 \mu \mathrm{g} . / \mathrm{ml}$. 24 hours after a ciose. The mininum inhibitory concentration for the organism was $1-2 \mu \mathrm{g} . / \mathrm{ml}$. and the minimum bactericidal concentration was the same.

As a result of experience with Case 1 the dosage was doubled by the intraventricular route and C.S.F. levels rose to about 1.5 $\mu \mathrm{g} . / \mathrm{ml}$. (residual after 24 hours), but the serum levels remained very low (less than $0.5 \mu \mathrm{g} . / \mathrm{ml}$. at any time). On the fourth day of treatment the intramuscular dose was also doubled and serum levels rapidly rose to between 1 and $2 \mu \mathrm{g} . / \mathrm{ml}$. During the next four days the organisms in the C.S.F. became less numerous and culture was sterile on the tenth day of treatment. Intraventricular therapy continued for another three days and intramuscular for a further week, during which time C.S.F. levels fell to zero and serum levels remained at between 1 and $2 \mu \mathrm{g} . / \mathrm{ml}$. There was no recurrence of the infection.

Protein and cells rose slightly on the second day of treatment and fell steadily thereafter. There was no evidence of toxicity of the drug.

\section{Case 3}

A baby who had a meningomyelocele repaired the day after birth developed meningitis three weeks later due to $\mathrm{Kl}$. aerogenes. The organism was sensitive only to cephaloridine and gentamicin, and treatment was begun with gentamicin at the double standard dose intramuscularly - that is, $2 \mathrm{mg} . / \mathrm{kg}$./day-and $1 \mathrm{mg}$. intraventricularly daily (Fig. 3).

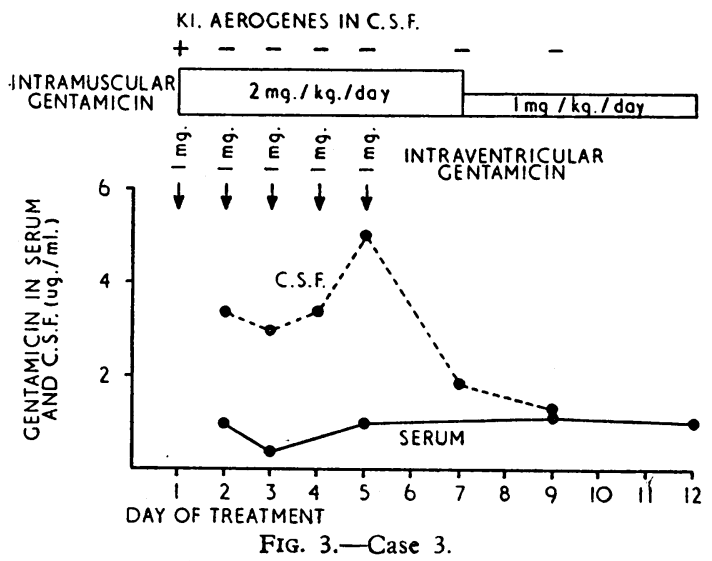

The C.S.F. was sterilized within 24 hours, and C.S.F. levels of gentamicin rose rapidly within that time to $3 \mu \mathrm{g} . / \mathrm{ml}$. The serum level also rose rapidly to $1 \mu \mathrm{g} . / \mathrm{ml}$. Intraventricular treatment continued for five days and intramuscular for seven days, with a further week of intramuscular dosage reduced to the standard rate of $1 \mathrm{mg} . /$ kg./day.

The infection did not recur and a Spitz-Holter valve was successfully inserted during the period of intramuscular treatment. No toxic or side effects were seen clinically or in the blood picture or urine.

\section{Comment}

In each case the sensitivity of the organism to the drug was checked at frequent intervals and the minimum inhibitory concentrations did not change. In Case 2 the minimum bactericidal concentration doubled during treatment but was still only ' $5-10 \mu \mathrm{g} . / \mathrm{ml}$. on the last isolation. In Case 3 a strain of Ps. pyocyanea colonizing the back wound was found to be resistant to $50 \mu \mathrm{g}$. of gentamicin per ml., an unusually high level for this organism; and in Case 2 a strain of $K l$. aerogines apparently identical with that in the C.S.F., and with the same minimum inhibitory concentration and 
minimum bactericidal concentration, was found in the patient's stools after treatment.

\section{Discussion}

From a comparison of the three cases it appears that in order to achieve and maintain an effective level of the drug in the C.S.F. it must not only be given intrathecally but a minimal level must also be maintained in the blood. In Case 1 this state of affairs was accomplished only after doubling the intramuscular dosage, and the necessity for this was borne out in Case 2 when the C.S.F. was sterilized only after doubling the dosage. In Case 3 rapid sterilization of the C.S.F. occurred, probably as a result of starting treatment on the increased dosage schedule.

It will be seen from Figs. 1-3 that without intraventricular administration it is most unlikely that an effective level could be reached in the C.S.F. by intramuscular dosage alone. This is in accordance with our experience in the treatment of similar conditions with other drugs. In the case reported by Klein et al. (1964), treated with intramuscular gentamicin alone the C.S.F. levels were very low and would be effective only against the most sensitive organisms. It should be borne in mind that the C.S.F. volume in these babies, all with some degree of hydrocephalus, was greater than normal, and smaller intraventricular doses would probably be appropriate in children with ventricles of normal size.

It has been reported by other workers that various side-effects of gentamicin have occurred, particularly when the blood level has exceeded about $10 \mu \mathrm{g} . / \mathrm{ml}$. It appears from our work on these three cases, and on children receiving the drug for other infections, that this level is unlikely to be reached, at least in young children, on normal or double intramuscular dosage. Indeed, it seems likely that in the treatment of tissue infections dependent on an effective blood level of the drug at least double the recommended intramuscular dose is necessary. It is possible that young children excrete the drug more rapidly than adults, but experience with other cases suggests that the danger of accumulation of the drug in the blood cannot be ignored, and that its use in children should be controlled at present by frequent serum assays.

In all three cases careful watch was kept for evidence of toxicity of the drug. No such effects were seen. The blood picture remained unchanged apart from the incidence of a leucocytosis in each case, and the urine showed no abnormalities. The blood urea was checked frequently in all cases and showed only minor fluctuations. All of these patients were small babies with congenital abnormalities of the nervous system, but no effects on the central nervous system were seen which might have been attributed to the use of gentamicin.

It has been our experience that colonization of valves used for the relief of hydrocephalus can never be eradicated by the use of antibiotics in the C.S.F. In Case 1, where this state of affairs existed, gentamicin also failed to sterilize the valve, though the ventricular C.S.F. was quickly sterilized.

\section{Conclusions}

In these three cases of ventriculitis due to organisms not easily dealt with by other drugs, gentamicin eradicated the infection successfully. It appears that in treating such infections it is essential to give the drug intraventricularly and to give simultaneously double the recommended intramuscular dose. No toxic effects were seen in these three cases, but as very little information exists on the use of gentamicin in children treatment should be controlled at present by frequent serum assays. The successful eradication of these three infections suggests that the use of gentamicin should be considered in infections of this kind where the choice of drugs is limited and results are often disappointing.

\section{Summary}

Three babies with meningitis and ventriculitis were successfully treated with gentamicin. Preliminary laboratory investigations showed gentamicin to be active against a wide range of organisms, particularly those commonly encountered in this condition. Frequent assays of cerebrospinal fluid and serum during treatent showed intraventricular administration to be essential together with a larger intramuscular dose than that recommended. Laboratory data and methods are presented in detail. No toxic effects attributable to the drug were seen, and it is suggested that the use of gentamicin should be considered in cases of this kind.

ADDENDUM.-Since this paper was written another similar case has been successfully treated with gentamicin. A baby with well-established $K l$. aerogenes meningitis and thick purulent C.S.F. was treated in the same way as Case 3. The C.S.F. was sterilized in 15 days and intramuscular therapy continued for a further month. In all, $270 \mathrm{mg}$. was given intramuscularly without side-effects.

We are grateful to our colleagues at Queen Mary's Hospital for Children for their help and co-operation in treating these patients, and particularly to Mr. H. B. Eckstein and Mr. D. M. Forrest, under whose care they were admitted. We are also indebted to the nursing staff for collection of numerous specimens.

The gentamicin used in this work was supplied by British Schering Limited.

\section{REFERENCES}

Barber, M., and Waterworth, P. M. (1966). Brit. med. 7., 1, 203.

Jao, R. L., and Jackson, G. G. (1964). Y. Amer. med. Ass., 189, 817. Sci., 248, 528 .

Lightbown, J. W., and Sulitzeanu, D. (1957). Bull. Wld Hlth Org., 17, 553.

Newman, R. L., and Stewart, G. T. (1964). Clin. Trials F., 1, 11.

Rosselet, J. P., et al. (1963). Antimicrobial Agents and Chemotherapy, $\mathrm{p} 14$.

Stone, H. H., Martin, J. D., Huger, W. E., and Kolb, Laura (1965). Surg. Gynec. Obstet., 120, 351

Wahlig, H. (1966). Methoden und Probleme der Mikrobiologischen Kontrolle pharmazeutischer Zubereitungsformen am Beispiel des Gentamycins. Unpublished data.

Weinenting W. Oden, E. M., and Wagman, G. H. (1963). Antimicrobial Agents and Chemotherapy, p. 1. 